\title{
Investigation on the surface roughness of the high steel material after wire electrical discharge machining process
}

\author{
M. Boujelbene ${ }^{1, *}$, S. Ezzdini $^{2}$, N. Elboughdiri ${ }^{1,3}$, W. Ben Salem ${ }^{4}$, W. Youssef ${ }^{1}$ \\ ${ }^{1}$ College of Engineering, University of Hail, Hail, Saudi Arabia \\ ${ }^{2}$ National School of Engineering, University of Tunis El Manar, Tunis, Tunisia \\ ${ }^{3}$ National School of Engineering Gabes, University of Gabes, Gabes, Tunisia \\ ${ }^{4}$ Preparatory Institute for Engineering Studies of Monastir, University of Monastir, Monastir, Tunisia
}

\section{A R T I C L E IN F O}

\section{Article history:}

Received 14 January 2017

Received in revised form

23 March 2017

Accepted 18 April 2017

\section{Keywords:}

WEDM

Surface roughness

Pulse on time

Peak current

Servo Voltage

ANOVA

\section{Introduction}

Electrical Discharge Machining (EDM) and Wire Electrical Discharge Machining (WEDM) are an important non-conventional manufacturing method used for hard to cut conductive material and has been accepted worldwide as a standard process in the manufacture of forming tools to produce plastics mouldings, forming dies, die casting, since it does not require cutting tools and allows machining involving hard, brittle, thin and complex geometry. However, EDM in general, is an unconventional machninig process which is widely used in the aerospace, medical industries, ordnance, automotive, and general engineering industries. It has a good as practically all areas of conductive material machining. The quality and cutting efficiency in wire EDM depends on the material and process parameters used (Boujelbene et al., 2009; Yan et al., 2014).

WEDM is a nontraditional, thermoelectric process which erodes material from the work piece

\footnotetext{
* Corresponding Author.

Email Address: mboujelbene@yahoo.fr (M. Boujelbene) https://doi.org/10.21833/ijaas.2017.06.018

2313-626X/C) 2017 The Authors. Published by IASE.

This is an open access article under the CC BY-NC-ND license

(http://creativecommons.org/licenses/by-nc-nd/4.0/)
}

(C) 2017 The Authors. Published by IASE. This is an open access article under the CC BY-NC-ND license (http://creativecommons.org/licenses/by-nc-nd/4.0/). by a series of discrete sparks between a work and tool electrode immersed in a liquid dielectric medium. These electrical discharges melt and vaporize minute amounts of the work material, which are then ejected and flushed away by the dielectric. WEDM is a specialized of the thermal machining process capable of accurately machining parts with varying hardness or complex shapes, which have sharp edges that are very difficult to be machined by the main stream machining processes. The electrical discharge generates impulsive pressure by dielectric explosion to remove the deleted material. The dielectric is fed continuously to the machining area to flush away the eroded particle (Mahapatra and Parnaik, 2007).

Since no cutting forces are present, WEDM is ideal for delicate parts. It is possible to make parts with taper or with different profiles at the top and bottom as the wire can be inclined. There is never any mechanical contact between the wire and workpiece (Puri and Bhattacharyya, 2005). Fig. 1 shows the schematic representation of WEDM process.

EDM has been an indispensable operation in the manufacturing process, it has been few years the centre of interest of several researchers (Ishida and Takeuchi, 2002; Junkar and Valentinčič, 1999; Jangra 
et al., 2010; Mahapatra and Parnaik, 2007; Oliaei and Karpat, 2016; Ramasawmy and Blunt, 2002).

Electrical Discharge Machining (EDM) and HighSpeed Cutting (HSC) are the two most commonly used technologies in tool production. The main advantage of HSC is higher productivity. On, the other hand, EDM is a slower process and it usually requires an electrode that is made especially for the machining of the given product. An advantage of EDM is the ability to machine small, even micro, features and curved holes (Ishida and Takeuchi, 2002). Nowadays, the main research on the EDM process is focused on micro machining and the improvement of surface roughness (Boujelbene et al., 2009; Tsai and Wang, 2001). There are still attempts to improve the automation of the EDM process.

To achieve a high removal rate and low electrode wear, rough machining parameters have to be selected according to the size of the eroding surface. These parameters are assembled in different machining regimes. The eroding surface is the projection of the engaged surface of the electrode to the plane perpendicular to the machining direction.

WEDM is a special form of EDM which is now used conventionally in manufacturing industries for generating intricate and complex profiles in hard metal alloys and metal matrix composites, with high degree of accuracy, without making any mechanical contact (Jangra et al., 2010). Application of WEDM has grown from simple making of tools and dies to the best alternative of producing micro-scale parts with the highest degree of dimensional accuracy and surface finish in various fields of engineering including automotive, aerospace, medical, optical, dental, jewelry industries, etc. (Ho et al., 2004).

Although, WEDM can machine hard composite material with more accuracy and precision, some unwanted surface flaws such as recast layer, heat affected zone, etc. have also been observed on machined surface. Since the melting and evaporation of material in WEDM is due to high heat energy, some part of this heat is transferred to the work material which develops the heat affected zone on work surface. The heat affected zone has different surface morphology as compared to base material. It consists of recast layer or white layer having hollow cavities and several micro-cracks due to thermal residual stresses (Lee and $\mathrm{Li}, 2003$; Wang et al., 2009).

In case of die manufacturing with WEDM, avoiding the surface degradation is the main concern to improve the die life. Therefore, one or more trim cuts (Sarkar et al., 2008) are required after rough cut, to minimize the surface defects and geometric inaccuracies. But sometimes, improper parameters setting during rough cutting operation may deteriorate the work surface very severely, which may not be improved considerably after one or more trim cuts (Juhr et al., 2004). Several studies have been conducted on EDM / WEDM to analyse the surface characteristics of the eroded work surfaces (Kahng and Rajurkar, 1997; Lee and Li, 2003;
Boujelbene et al., 2009; Veldhuis et al., 2010; Ramasawmy and Blunt, 2002).

All these studies explored the effect of process parameters on depth of recast layer and heat affected zone. But in case of intricate machining on WEDM such as in die cutting, some surface area remains un-machined after rough cutting operation, which has not been investigated so far. This unmachined area named as surface projection, if not eliminated from die surface, may affect severely the die performance and the quality of the final components.

Therefore, the aim of this paper is to present some investigations on surface projections appeared after rough cutting operation in intricate machining on WEDM. In this study a Taguchi's L27 orthogonal table was applied to plan the experiments. Three controlling factors with three levels for each factor were selected and to optimize the two responses; the surface roughness $(\mathrm{Ra})$.

\section{Experimental procedures}

The main aim of the experimental work was to investigate the effects of cutting parameters in WEDM, on the Ra.

\subsection{Material and methods}

The material studied here is high alloyed steel (type EN X160CrMoV12 / AISI D2). This steel is generally used for the manufacturing of moulds, stamps used in presses, deep-drawing dies, and other tools. The chemical composition and thermomechanical properties are given in the Tables 1 and 2 , respectively.

Fig. 1 shows the experimental arrangement and the measured surface roughness.

The sizes of workpieces were $8 \times 10 \times 17 \mathrm{~mm}$.

The experiments were performed on Actspark 2001 Robofil, Agie Charmilles, and Wire electric discharge machine tools shown in Fig. 1.

The fixed processes parameters used during experimentation are as below:

- Workpiece: High strength and high alloy steel $\mathrm{X} 155 \mathrm{CrMoV} 12$. The structure of the steel consists of martensite with a distribution of primary carbide type $\mathrm{M}_{7} \mathrm{C}_{3}$ and secondary carbide type $\mathrm{M}_{23} \mathrm{C}_{6}$, as shown in Fig. 2.

- Electrode (Tool): $250 \mu \mathrm{m}$ Diameter Tungsten and molybdenum wire.

- Dielectric: Deionised water.

- Pulse-off time $\mathrm{T}_{\mathrm{OFF}}=15 \mu \mathrm{s}$

The surface roughness was measured of the machined surface using a roughness tester (2D) Hommel T1000, in terms of arithmetic average roughness $\mathrm{Ra}$. The length examined is $4 \mathrm{~mm}$ and we used the range $1.6-8 \mu \mathrm{m}$ as the control criterion for finish WEDM. 


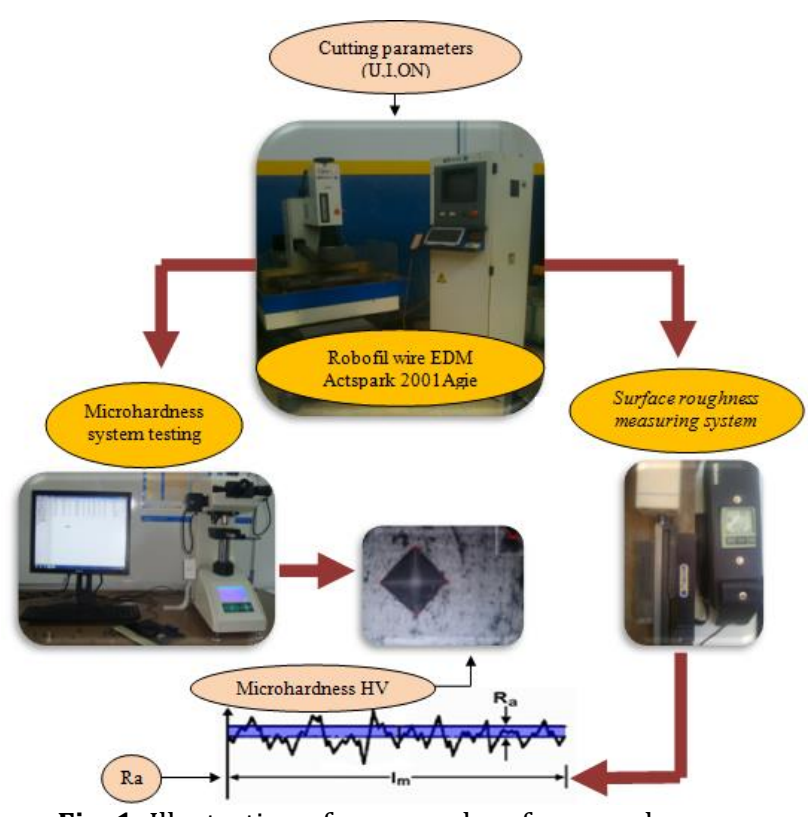

Fig. 1: Illustration of measured surface roughness

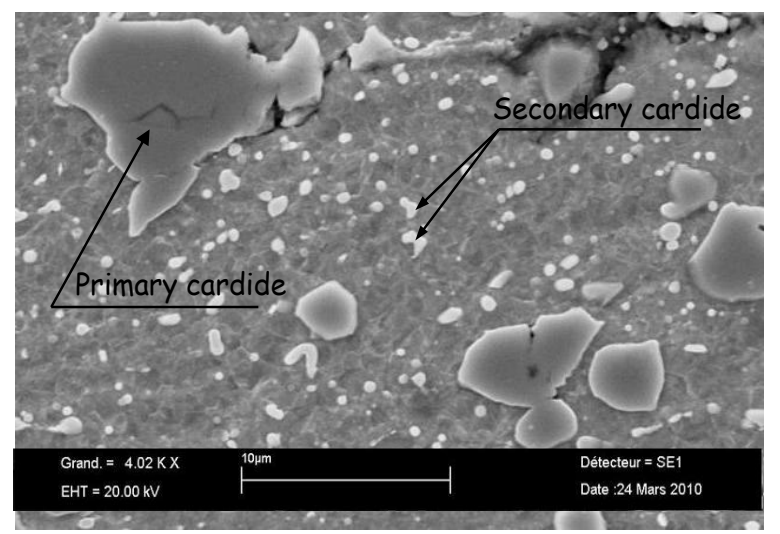

Fig. 2: Structure of material X155CrMoV12 / AISI D2 steel

The level of cutting parameters ranges and the initial parameter values were chosen from the manufacturer's handbook recommended for the tested material. The control factors, their designated symbols and range are given in cutting in Table 3 .

Three levels of servo voltage $U$, three levels of peak current I and three levels of pulse on time ON or Ton, were chosen for the examination of them impact on performance parameter of the Ra.

Table 1: Chemical composition of work piece material X155CrMoV12

\begin{tabular}{cc}
\multicolumn{3}{c}{ C155CrMoV12 } \\
\hline C & 1.58 \\
Si & 0.26 \\
Mn & 0.32 \\
P & 0.01 \\
S & 0.01 \\
Cr & 12.00 \\
Mo & 0.16 \\
V & 0.40 \\
W & 0.01 \\
\hline
\end{tabular}

Table 2: Mechanical properties of work piece material $\mathrm{X} 155 \mathrm{CrMoV} 12$

\begin{tabular}{ccccc}
\hline \multirow{3}{*}{ Material } & \multicolumn{4}{c}{ Mechanical properties } \\
\cline { 2 - 5 } & UTS & $0.2 \%$ YS & E & Hardness \\
& $(\mathrm{MPa})$ & $(\mathrm{MPa})$ & $\%$ & $(\mathrm{HV})$ \\
\cline { 1 - 3 } X155CrMoV12 & 720 & 630 & 20 & 260 \\
\hline
\end{tabular}

\subsection{Experimental design using the taguchi method}

A variety of industries have employed the Taguchi method in past years to improve products or manufacturing processes. It is a powerful and effective method used to solve challenging quality problems. The Taguchi method has been used quite successfully in several industrial applications such as optimizing manufacturing processes or industries electronics or designing electrical / mechanical components (Yang and Chang, 2006; Lin et al., 2007; Hwang et al., 2009). However, Taguchi's parameter design method can only find the best set of specified process parameter level combinations for discrete process parameter values. The application of a conventional Taguchi parameter design method is unreasonable when the process parameter variable is continuous and cannot help engineers obtain optimal process parameter settings. Therefore, efficient analytical methods and tools are necessary to efficiently and rapidly analyze process parameters and control product quality. Recently, the Response Surface Methodology (RSM) method has been used quite successfully for optimizing manufacturing processes, for example in mechanical production and designing electrical components and industrial production parts. RSM is a collection of statistical and mathematical methods that are useful for modeling and analyzing engineering problems. In this technique, the main objective is to optimize the response surface that is influenced by various process parameters for example cutting speed, feed rate. RSM also quantifies the relationship between the controllable input parameters; servo voltage U, peak current (I) and pulse on time ( $\left.\mathrm{T}_{\mathrm{ON}}\right)$, in WEDM processes and the obtained response surfaces ( $\mathrm{Ra}$ ) used RSM to study the optimization of Wire Electrical Discharge Machining processes for manufacturing automotive parts.

Table 3: Important process parameters and their levels

\begin{tabular}{cccccc}
\hline \multirow{2}{*}{ Factor } & Parameters & Unit & \multicolumn{3}{c}{ Levels } \\
\cline { 4 - 6 } A & $\begin{array}{c}\text { Pulse on } \\
\text { time }\end{array}$ & Level 1 & Level 2 & Level 3 \\
B & $\begin{array}{c}\text { Peak } \\
\text { current } \\
\text { Servo } \\
\text { voltage }\end{array}$ & $\begin{array}{c}\text { Ampere } \\
(\mathrm{A})\end{array}$ & 8 & 16 & 24 \\
C & Volts (V) & 10 & 25 & 40 \\
\hline
\end{tabular}

The experimental matrix with variables was employed to develop twenty seven experiments (Table 4). For every experiment, one sample was used under time regulated condition. L27 orthogonal array were used to reduce number of the experience. The design of experiments (DOE) and measured Ra values are shown in Table 4.

Taguchi method is widely used for optimizing industrial/production process. The Taguchi design optimization method can be divided into three stages: (a) system design, (b) parameter design and (c) tolerance design. Among the three stages, the 
parameter design stage is considered to be the important stage (Taguchi et al., 1989; Ross, 1996).

The experimental design proposed by taguchi involves using orthogonal arrays to organize the parameters affecting the process and the levels at which they should be varied. The taguchi method tests pairs of combinations instead of testing all possible combination. This allows determining the major factors affecting the output, with a minimum amount of experimentation.

\section{Results and discussion}

\subsection{Surface roughness}

Generally, all characterization methods perform an intrinsic filtering, which define the bandwidth of spatial surface wavelengths from which the measured values are evaluated (Stover, 2012). For mechanical methods the bandwidth filtering is generally due to the tip radius and scans area (Stover, 2012), while for optical methods it is mainly due to angular constraints in the detection system. This study will determine the filtering bandwidths for the method, and ensure that values and describe the roughness parameter.

A wide range of roughness parameters can be used to describe a given surface (De Chiffre et al., 2000). The most common parameters are calculated from line profiles according to the ISO 4287 standard (but due to an increased use of 3D profilers a set of complimentary area roughness parameters have been defined in the ISO 25178-2 standard (ISO, 1997).

Table 4: Experimental result

\begin{tabular}{|c|c|c|c|c|c|}
\hline \multirow{2}{*}{ Run No. } & \multicolumn{4}{|c|}{ Process parameters } & \multirow{2}{*}{$\begin{array}{l}\text { Performanc } \\
\text { e parameter } \\
\text { Ra }(\mu \mathrm{m})\end{array}$} \\
\hline & I (A) & $\mathrm{U}(\mathrm{V})$ & $\mathrm{T}_{\mathrm{ON}}(\mu \mathrm{s})$ & $\mathrm{T}_{\mathrm{OFF}}(\mu \mathrm{s})$ & \\
\hline 1 & 4 & 10 & 8 & 15 & 2 \\
\hline 2 & 4 & 10 & 16 & 15 & 3.69 \\
\hline 3 & 4 & 10 & 24 & 15 & 4.99 \\
\hline 4 & 4 & 25 & 8 & 15 & 2.25 \\
\hline 5 & 4 & 25 & 16 & 15 & 3.94 \\
\hline 6 & 4 & 25 & 24 & 15 & 5.89 \\
\hline 7 & 4 & 40 & 8 & 15 & 2.29 \\
\hline 8 & 4 & 40 & 16 & 15 & 4.08 \\
\hline 9 & 4 & 40 & 24 & 15 & 5.87 \\
\hline 10 & 6 & 10 & 8 & 15 & 3.27 \\
\hline 11 & 6 & 10 & 16 & 15 & 4.14 \\
\hline 12 & 6 & 10 & 24 & 15 & 4.86 \\
\hline 13 & 6 & 25 & 8 & 15 & 4.02 \\
\hline 14 & 6 & 25 & 16 & 15 & 5.58 \\
\hline 15 & 6 & 25 & 24 & 15 & 6.68 \\
\hline 16 & 6 & 40 & 8 & 15 & 4.36 \\
\hline 17 & 6 & 40 & 16 & 15 & 6.01 \\
\hline 18 & 6 & 40 & 24 & 15 & 6.98 \\
\hline 19 & 8 & 10 & 8 & 15 & 3.86 \\
\hline 20 & 8 & 10 & 16 & 15 & 4.35 \\
\hline 21 & 8 & 10 & 24 & 15 & 4.78 \\
\hline 22 & 8 & 25 & 8 & 15 & 5.01 \\
\hline 23 & 8 & 25 & 16 & 15 & 6.25 \\
\hline 24 & 8 & 25 & 24 & 15 & 6.89 \\
\hline 25 & 8 & 40 & 8 & 15 & 5.47 \\
\hline 26 & 8 & 40 & 16 & 15 & 6.74 \\
\hline 27 & 8 & 40 & 24 & 15 & 764 \\
\hline
\end{tabular}

In this study, the line parameters are used as these are more appropriate for the 2D surfaces analyzed. The specific parameter used in the study $\mathrm{Ra}$, is the surface roughness or the arithmetic mean of the absolute values of the profile deviations (Yi) from the mean line (Eq. 1).

$R a=\frac{1}{N} \sum_{i=1}^{N}|Y i|$

For ANSI, Ra is defined over the entire evaluation length will be noted as required.

To study the evolution of the average roughness $\mathrm{Ra}$, we measured the roughness $\mathrm{Ra}$ of 27 samples using a roughness meter (2D) Hommel T1000 in order to achieve representative curves depending on the servo voltage SV or U, the discharge current $I_{P}$ or $I$ and the pulse on time $\mathrm{T}_{\mathrm{ON}}$ or $\mathrm{ON}$ in fixing each time one of the three parameters and varying the other two, which are shows in the following Figs. 3, 4 and 5.

Fig. 3 shows that the pulse on time Ton plays an important role on the surface quality of machined pieces of high alloy steel and especially a significant effect on the average roughness Ra.

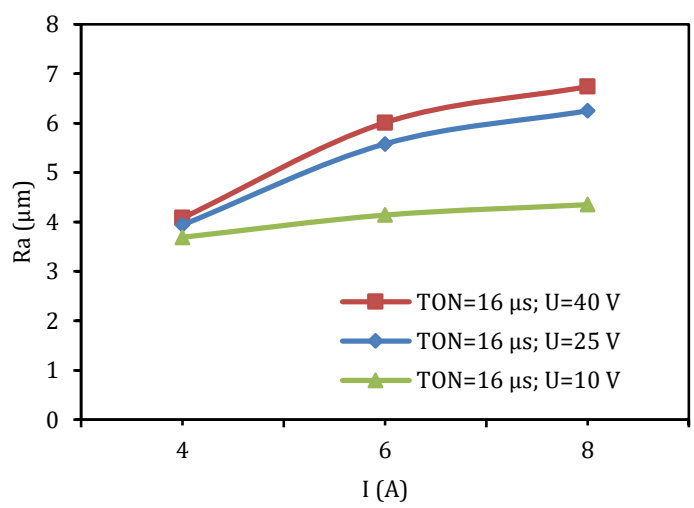

Fig. 3: Evolution of the surface roughness Ra according to the discharge intensity I for three servo voltage values with $\mathrm{T}_{\mathrm{ON}}=16 \mu \mathrm{s}$

This figure shows that the average roughness Ra increases with the evolution of the peak current $I$ in a time $T_{O N}=16 \mu \mathrm{s}$. At this level and for a peak current which varies between 4 and $8 \mathrm{~A}$, the quality of surface weakly exchange especially for servo voltage $U=10 \mathrm{~V}$ (Fig. 3).

Fig. 3 shows the evolution of surface roughness $\mathrm{Ra}$ as function of the discharge intensity for three servo voltages values $\mathrm{U}=10 \mathrm{~V} ; \mathrm{U}=25 \mathrm{~V}$ and $\mathrm{U}=40 \mathrm{~V}$ with a pulse on time $\mathrm{T}_{\mathrm{ON}}=16 \mu \mathrm{s}$. It is noted that the roughness surface increases with the increasing peak current. Fig. 4 shows the evolution of surface roughness $\mathrm{Ra}$ according to the starting voltage for three values of the pulse on time $\mathrm{T}_{\mathrm{ON}}=8 \mu \mathrm{s}$; $\mathrm{T}_{\mathrm{ON}}=16$ $\mu s ; \mathrm{T}_{\mathrm{ON}}=24 \mu \mathrm{s}$ with $\mathrm{I}=8 \mathrm{~A}$ and it is noted that the roughness surface increases when the servo voltage increases.

However, Fig. 4 shows that the surface roughness $\mathrm{Ra}$ depends on the servo voltage at a current intensity I = $8 \mathrm{~A}$. The more servo voltage $\mathrm{U}$ increases, the average roughness $\mathrm{Ra}$ increases. This increase is less significant if the pulse on time is relatively low $\left(\mathrm{T}_{\mathrm{ON}}=8 \mu \mathrm{s}\right)$. 
Finally the Fig. 5 shows the evolution of the surface roughness $\mathrm{Ra}$ according to the pulse on time for three servo voltage value $U=10 \mathrm{~V} ; \mathrm{U}=25 \mathrm{~V}$ and $\mathrm{U}=40 \mathrm{~V}$ with a discharge current $\mathrm{I}=6 \mathrm{~A}$ and it observed that the roughness has a significant increase.

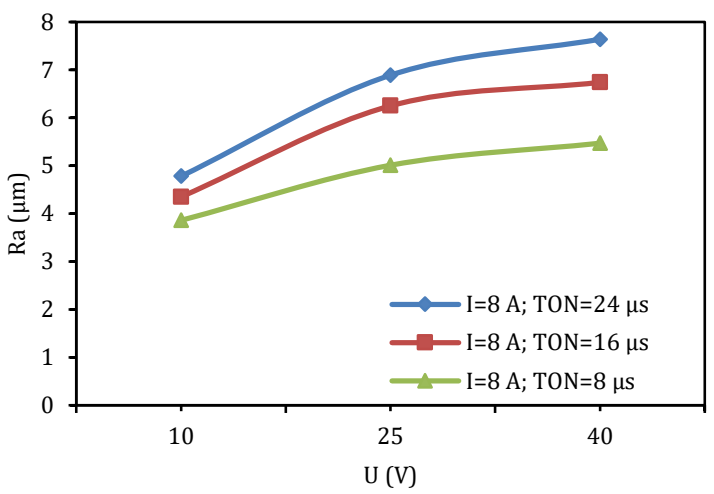

Fig. 4: Evolution of the surface roughness Ra according to the servo voltage for three values of the pulse time with $\mathrm{I}=$ $8 \mathrm{~A}$

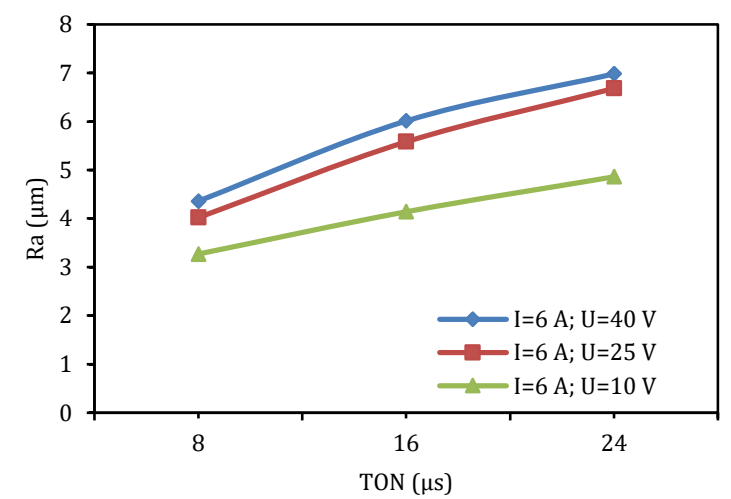

Fig. 5: Evolution of the surface roughness Ra according to the pulse on time for three servo voltage value and a discharge peak current $\mathrm{I}=6 \mathrm{~A}$

In order to analyze the results of the experimental runs, analysis of variance (ANOVA) is carried out to examine the influence of cutting parameters on the surface roughness average. If some cutting parameters do not significantly affect the surface roughness $\mathrm{Ra}$, they can be fixed to the recommended values of analyzers and excluded in predictive model generation of optimization processes. This will increase the efficiency of the optimization process. The analysis of variance (ANOVA) is conducted and the results are shown in Table 4, lists the ANOVA result for roughness average (Ra).

To examine which factor has a significant effect on the surface roughness values in each area, we used the statistical method ANOVA and the result for surface roughness $\mathrm{Ra}$ is given in Table 4 .

The effects of the roughness parameters can be graphically explained by the effect curves (Fig. 6) and those interactions (Fig. 7).

It is noted that the Ton pulse time has a greater effect than the servo voltage $U$ and the peak current I.
The interaction diagram shows the impact exerted by the variation values of a factor to another. It is very important to assess interactions, as they can magnify or diminish main effect (Figs. 6 and 7).

Table 4: ANOVA for Ra

\begin{tabular}{cccccc}
\hline $\begin{array}{c}\text { Taurce } \\
\text { of } \\
\text { variation }\end{array}$ & df & SS & MS & $F_{\text {test }}$ & F analytic \\
\hline A & 2 & 77.76 & 38.88 & 5254.40 & $>3.32$ \\
B & 2 & 22.81 & 11.40 & 1540.54 & $>3.32$ \\
C & 2 & 24.24 & 12.12 & 1637.83 & $>3.32$ \\
AB & 4 & 18.60 & 9.3 & 1256.75 & $>2.69$ \\
AC & 4 & 15.74 & 7.87 & 1063.51 & $>2.69$ \\
BC & 4 & 5.88 & 2.94 & 397.29 & $>2.69$ \\
ABC & 8 & 11.08 & 5.54 & 748.64 & $>2.09$ \\
Error & 27 & 0.2 & 0.0074 & & \\
\hline
\end{tabular}

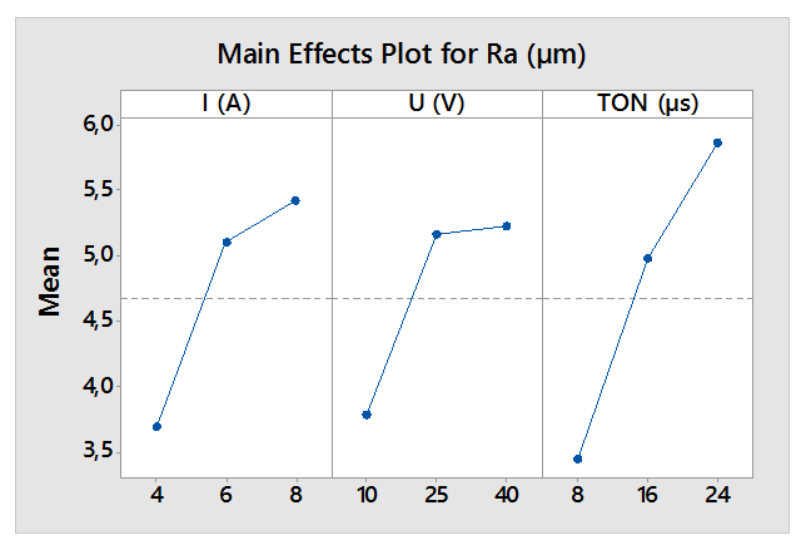

Fig. 6: Curves of the effects of voltage, current and pulse time on $\mathrm{Ra}$

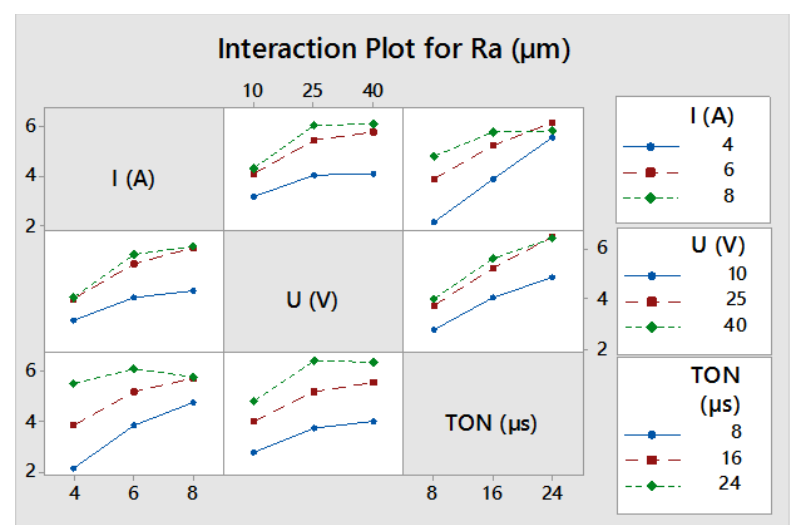

Fig. 7: The interaction Curves of the effects of voltage, current and pulse time on $\mathrm{Ra}$

Fig. 6 shows the curves of the effects of servo voltage; peak current and pulse on time Ton on the surface roughness Ra.

Fig. 7 shows the interaction curves of the effects of servo voltage, current and pulse on time $\mathrm{T}_{\mathrm{ON}}$ on the surface roughness $\mathrm{Ra}$.

In cases where only three factors are important, the answer is given as Eq. 2:

$\operatorname{Ln}(\mathrm{Y})=\mathrm{b}_{0}+\mathrm{b}_{1} \mathrm{X}_{1}+\mathrm{b}_{2} \mathrm{X}_{2}+\mathrm{b}_{3} \mathrm{X}_{3}+\mathrm{b}_{12} \mathrm{X}_{1} \mathrm{X}_{2}+\mathrm{b}_{23} \mathrm{X}_{2} \mathrm{X}_{3}+$ $\mathrm{b}_{13} \mathrm{X}_{1} \mathrm{X}_{3}+\mathrm{b}_{123} \mathrm{X}_{1} \mathrm{X}_{2} \mathrm{X}_{3}$

$X i$ is replaced by their value depending on $x i$.

Finally, the model of the surface roughness $R a$ is given as Eq. 3: 
$\mathrm{Ra}=0,9237 \mathrm{TON}^{1.82} \times \mathrm{U}^{1.46} \times \mathrm{I}^{0.68} \times(\mathrm{TON} \times \mathrm{U})^{0.05} \times$

$(\mathrm{U} \times \mathrm{I})^{-1.1} \times(\mathrm{TON} \times \mathrm{I})^{0.758} \times(\mathrm{TON} \times \mathrm{U} \times \mathrm{I})^{0.039}$

\section{Conclusion}

Experiments were performed on WEDM using tungsten and molybdenum wire and D2 tool steel as work-piece. Numbers of experiments were reduced by Taguchi method design. The objective of the research is to investigate the WEDM performances on the mechanical properties of a considered hardened steel material used in the automotive applications. The purpose of this study is to enable the optimization of WEDM parameters according to industrial constraints. This study has also an important impact on control of energy consumption in machining production process and can be benefic for reduction of WEDM production cost. The study and analysis of the results of experiments conducted during the EDM wire steel alloyed X155CrMoV4 show that electrical parameters affect the results of the process so that the nature of the electrode used and that the work piece. However the main results reached as a result of this study include:

- The surface roughness Ra increase with increasing of the servo voltage $U$, and this increase is large when the voltage is $10 \mathrm{~V}$ to $25 \mathrm{~V}$. Beyond this value, low roughness believe.

- Increasing the intensity of the peak current I, allows to degrade the surface quality of parts machined by WEDM for given speeds.

- The pulse on time $T_{O N}$ or $O N$, is a very important parameter for the WEDM, its increase causes a considerable variation in the parameters of the surface roughness $\mathrm{Ra}$ and therefore, obtaining rough surfaces.

- The peak current intensity $I$ is also an important machining parameter, since it can also easily modify the surface hardness of the machined surface.

\section{Acknowledgement}

The authors would like to thank the Deanship of the Scientific Research of University of Hail, Kingdom of Saudi Arabia, KSA, for funding and supporting this research project (0150387).

\section{List of symbols}

WEDM: Wire electrical discharge machining

SR or Ra: $\quad$ Surface roughness $(\mu \mathrm{m})$

Ton or ON: $\quad$ Pulse on time $(\mu \mathrm{s})$

Toff or OFF: $\quad$ Pulse off time $(\mu \mathrm{s})$

SV or U: $\quad$ Servo Voltage (V)

Ip or I: $\quad$ Peak current $(A)$

ANOVA: $\quad$ Analysis of Variance

HAZ: Heat Affected Zone

\section{References}

Boujelbene M, Bayraktar E, Tebni W, and Ben Salem S (2009). Influence of machining parameters on the surface integrity in electrical discharge machining. Archives of Materials Science and Engineering, 37(2): 110-116.

De Chiffre L, Lonardo P, Trumpold H, Lucca DA, Goch G, Brown CA Raja J, and Hansen HN (2000). Quantitative characterisation of surface texture. CIRP Annals-Manufacturing Technology, 49(2): 635-644, 642-652.

Ho KH, Newman ST, Rahimifard S, and Allen RD (2004). State of the art in wire electrical discharge machining (WEDM). International Journal of Machine Tools and Manufacture, 44(2): 1247-1259.

Hwang YK, Lee CM, and Park SH (2009). Evaluation of machinability according to the changes in machine tools and cooling lubrication environments and optimization of cutting conditions using Taguchi method. International Journal of Precision Engineering and Manufacturing, 10(3): 65-73.

Ishida T and Takeuchi Y (2002). L-shaped curved hole creation by means of electrical discharge machining and an electrode curved motion generator. International Journal of Advanced Manufacturing Technology, 19(4): 260-265.

ISO (1997). Geometrical product specifications (GPS)—surface texture: Profile method: Terms, definitinos and surface texture parameters. 4287, International Organization for Standardization, Geneva, Switzerland.

Jangra K, Jain A, and Grover S (2010). Optimization of multiplemachining characteristics in wire electrical discharge machining of punching die using grey relational analysis. Journal of Scientific and Industrial Research, 69: 606-612.

Juhr H, Schulze HP, Wollenberg G, and Kunanz K (2004). Improved cemented carbide properties after wire-EDM by pulse shaping. Journal of Material Processing Technology, 149(1): 178-183.

Junkar M and Valentinčič J (1999). Towards intelligent control of electrical discharge machining. Journal of Manufacturing Systems, 29(5): 453-457.

Kahng CH and Rajurkar KP (1997). Surface characteristics behaviour due to rough and fine cutting by EDM. Annals of the CIRP, 25(1): 77-82.

Lee SH and Li XP (2003). Study of the surface integrity of the machined workpiece in the EDM of tungsten carbide. Journal of Material Processing Technology, 139(1): 315-321.

Lin CT, Yang LD, and Chow HM (2007). Study of magnetic abrasive finishing in free-form surface operations using the Taguchi method. The International Journal of Advanced Manufacturing Technology, 34(1-2): 122-130.

Mahapatra SS and Parnaik A (2007). Optimization of wire electrical discharge machining (WEDM) process using Taguchi method. The International Journal of Advanced Manufacturing Technology, 34(9): 911-925.

Oliaei SNB and Karpat Y (2016). Fabrication of PCD mechanical planarization tools by using $\mu$-wire electrical discharge machining. Procedia CIRP, 42: 311-316.

Puri AB and Bhattacharyya B (2005). Modelling and analysis of white layer depth in a wire-cut EDM process through response surface methodology. The International Journal of Advance Manufacturing Technology, 25(3-4): 301-307.

Ramasawmy $\mathrm{H}$ and Blunt L (2002). 3D surface topography assessment of the effect of different electrolytes during electrochemical polishing of EDM surfaces. International Journal of Machine Tools and Manufacture, 42(5): 567-574.

Ross J (1996). Taguchi technique for quality engineering. McGrawHill, New York, USA.

Sarkar S, Sekh M, Mitra S, and Bhattacharyya B (2008). Modelling and optimization of wire electrical discharge machining of $\gamma$ TiAl in trim cutting operation. Journal of Material Processing Technology, 205(1): 376-387.

Stover JC (2012). Optical scattering: Measurement and analysis. SPIE Press, Bellingham, USA. 
Taguchi G, El Sayed M, and Hsaing C (1989). Quality engineering and quality systems. McGraw Hill, New York, USA.

Tsai KM and Wang PJ (2001). Predictions on surface finish in electrical discharge machining based upon neural network models. International Journal of Machine Tools and Manufacture, 41(10): 1385-1403.

Veldhuis SC, Dosbaeva GK, Elfizy A, Fox-Rabinovich GS, and Wagg $T$ (2010). Investigation of white layer formation during machining of powder metallurgical Ni-based ME 16 Superalloy. Journal of Material Engineering and Performance, 19(7): 1031-1036.
Wang YQ, Afsar AM, and Song JI (2009). Optimization of brazing conditions for OFHC Cu and ASTM A501 low carbon steel by Taguchi method. International Journal of Precision Engineering and Manufacturing, 10(3): 97-104.

Yan J, Watanabe K, and Aoyama T (2014). Micro-electrical discharge machining of polycrystalline diamond using rotary cupronickel electrode. CIRP Annals-Manufacturing Technology, 63: 209-212.

Yang YK and Chang TC (2006). Experimental analysis and optimization of a photo resist coating process for photolithography in wafer fabrication. Microelectronics Journal, 37(8): 746-751. 